\title{
Comparative Evaluation of Esthetic Materials Used for Fixed Partial Prosthesis Placed on Vital Abutments on The Periodontal Status: A One Year Retrospective Follow-Up
}

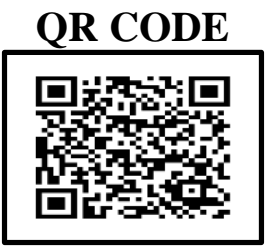

SHREYA SHETTY**1, KARUNAKAR SHETTY², RAGHAD TAYEB3, JUMANA ABDOU3, BADARIYA FETAIHI3, KHAMRUNISSA HUSSAIN SHEIKH4

BACKGROUND: The replacement of missing teeth with fixed partial dentures is largely dependent upon the health and stability of the surrounding periodontal structures. FPDs are often prepared on vital teeth as abutments. Esthetic materials have become popular in fixed prosthodontics today.

AIM: The present study aimed to assess the long-term effect and tissue responses of various types of fixed partial prosthesis placed on vital abutment teeth on the periodontal parameters both clinically and radiographically.

MATERIALS AND METHOD: Following ethical committee approval, the study group comprised of 87 abutment teeth in 41 systemically healthy patients ( 24 males and 17 females) aged between 18 - 45 years who had received 3 unit fixed prosthesis(IPS empress, PFM or zirconia), having equigingival margins using vital teeth as abutments. The following parameters were assessed at the time of bridge placement and 1 year follow up - CAL, Probing depth, Distance between CEJ/cervical crown margin and alveolar crest of the abutment teeth(radiograph).

RESULTS: Statistical analysis carried out by SPSSV22 software revealed significant changes in clinical parameters with IPS empress and radiographic parameters with PFM and Zirconia from time of bridge placement till the 1 year follow up. $(\mathrm{P}<0.05)$.

CONCLUSION: There seemed to be favorable responses of the periodontal tissues to the various esthetic materials used on vital abutments of FPDs.

KEYWORDS: Vital Abutments, Periodontal Status, Bone Loss, PFM, Zirconia

\section{INTRODUCTION}

Replacement of missing teeth with a fixed prosthesis(FPD) is one of the most popular treatment options available today. The abutments used for FPDs may be vital or non-vital. Sound periodontium is of utmost importance to ensure their long-term stability. ${ }^{1}$ Most often, all surfaces of vital abutments are prepared to support the retainers of the fixed partial denture. Post-cementation hypersensitivity in these abutments is a common complaint among patients receiving fixed prosthesis. Post- cementation sensitivity rates varied widely in clinical studies ranging from a low of $3 \%$ to a high of $34 \% .^{2}$

Research has shown that non-vital abutments (endodontically treated teeth) may not work as well as vital abutments for a fixed prosthesis. ${ }^{3}$ On the other hand, evidence has also revealed that the survival of the vital pulp in teeth restored with a single-unit metal ceramic crown $(\mathrm{CMC})$ was significantly higher than those serving as an abutment of a fixed-fixed bridge. However, it has also been observed that maxillary anterior teeth used as bridge abutments had a higher rate of pulpal necrosis than any other tooth types. ${ }^{4} \mathrm{De}$ Backer et al. (2007) concluded that endodontically treated abutments resulted in more FDP failures than vital abutments. ${ }^{5}$

Selection of a suitable abutment for fixed prosthesis is critical as FPDs transmit forces through the abutments to the periodontium. Successful selection of abutments for fixed partial dentures requires sensitive diagnostic ability and a thorough knowledge and understanding of anatomy, ceramics, the chemistry and physics of dental materials, metallurgy, Periodontics, phonetics, physiology, radiology and the mechanics of oral function $^{6}$ which is crucial in the development of treatment plan with predictable prognosis. It is paramount to focus on the qualities of FPDs and crowns in order to reduce the periodontal inflammation and ensure long term prognosis of the prosthesis as periodontal health governs FPD survival to a large extent.

PFM crowns have been popular FPD materials for a long time. The last four decades have seen various alternatives to PFM crowns to overcome their esthetic limitations. ${ }^{7}$ All-ceramic crowns can be made from different types of ceramic materials such as lithium disilicate, zirconia, leucite-reinforced glass, and glassinfiltrated alumina, and such newer metal-free crowns are increasingly being used in dental practice. ${ }^{7}$ Ceramic abutments, fabricated from yttrium stabilizedzirconium oxide $\left(\mathrm{ZrO}_{2}\right)$, have been developed for their

(C) Shreya Shetty et al. This is an open access article distributed under the terms of the Creative Commons Attribution License CC-BY-NC 4.o, which permits unrestricted use, distribution and reproduction in any medium, provided the use is not commercial and the original author(s) and source are cited. 
color, (similar to that of teeth), high loading strength, tissue tolerability, and intrasulcular design enhancement. ${ }^{8}$ As a result of patient demand, veneers and crowns are currently available in $\mathrm{ZrO}_{2}$ or, recently, in lithium disilicate (LS2) ceramic. ${ }^{9}$

Thus, the aim of the present cross-sectional study was to assess the effect of various types of materials used in FPD on the periodontal status of vital abutment teeth.

\section{MATERIALS AND METHODS:}

Following approval from the institutional Ethical Committee at ISNC, Jeddah, nearly 200 patients treated with 3 unit FPDs in the period between January 2017 and December 2018 were screened. Of these 41 patients were selected for the study based on the following inclusion criteria:

(1) Adults who were systemically healthy, non-smokers, and who had 3 unit FPDs for at least one year and

(2) Abutment teeth that were vital and had equigingival margins with plaque and gingival indices less than $10 \%$.

Informed consents were obtained from the enrolled subjects after explaining the nature of the study and possible risks involved.

Clinical and radiographic measurements were made on the abutment teeth at baseline, following placement of bridge and at 1 year follow up visit with a UNC 15 periodontal probe as follows:

1. Probing depth( facial and lingual)

2. Clinical attachment level(CAL) ( facial and lingual)

A total of 6 measurements, 3 each on the facial and lingual surfaces and an average of these was used as a final value.

The following measurements were made on the radiographs on the abutment teeth using grids:

1. Distance from CEJ to alveolar crest. (baseline)

2. Distance from cervical margin of crown to alveolar crest. ( FPD placement and follow up)

Care was taken to ensure that the radiographic techniques and the radiographs were standardized to maintain homogeneity in measurements.

The linear distances in two dimensions were measured using the following mathematical formula: $\frac{\text { Actual distance between two points (giid) }}{\text { Measured distance between two points (gridd) }}=\frac{\text { Actual distance between two points (anatomic) }}{\text { Measured distance between two points (anatomic) }}$

The distance measured was between 2 points cementoenamel junction/ crown margin to alveolar crest. The patients were given appropriate oral hygiene instructions to ensure maintenance of low plaque scores throughout the duration of the study.

\section{RESULTS:}

Statistical analysis was carried out using SPSSV22 software. Since the data was normal, paired ' $t$ ' tests were used to assess the differences in the means of the clinical parameters of each material at the different time intervals.

IPS EMPRESS: [Table $1(a) \&(b)]$ The abutment teeth receiving IPS empress crowns revealed a statistically significant reduction in probing depth from time of placement to post 1 year follow up period. $(\mathrm{P}<0.005)$ but not with regard to $\mathrm{CAL}(\mathrm{P}>0.05)$. However, no significant changes were observed in the bone levels seen in the radiographs in the 1 year period.

Porcelain fused to Metal (PFM): [Table 2(a)\&(b)] There were no significant changes in probing depth and CAL in the abutment teeth receiving PFM crowns in the 1 year follow up period.(P>0.05). However, there was a significant improvement in radiographic bone levels ( $\mathrm{P}<0.001$ ).

Zirconia: [Table 3(a)\&(b)] There were no significant changes in probing depth and CAL in the abutment teeth receiving Zirconia crowns in the 1 year follow up period. $(\mathrm{P}>0.05)$. However, there was a significant improvement in radiographic bone levels $(\mathrm{P}<0.05)$.

\section{DISCUSSION:}

Alsinaidi et al. 2014 indicated that in subjects with fixed partial dentures, the abutment teeth are more prone to periodontal inflammation than the non-abutment teeth. Additionally, the individual's age, duration of insertion of fixed partial dentures and location of the crown margins affect the periodontal health of the abutments. Studies have also suggested that the type of restorative material may also affect the periodontal status of teeth. ${ }^{10-}$ 11

There is a growing popularity of the newer esthetically and biologically compatible materials used in fixed partial dentures today. Although PFM has been a popular choice for a long time, newer esthetic materials 


\begin{tabular}{|l|l|c|c|c|c|}
\hline \multicolumn{7}{|c|}{ Paired Samples Statistics } \\
\hline \multirow{2}{*}{ Pair 1 } & \multicolumn{7}{|c|}{ Mean } & N & Std. Deviation & Std. Error Mean \\
& PD 1(F/L) & 1.785 & 13 & .4413 & .1224 \\
& PD 2 (F/L) & 1.454 & 13 & .3821 & .1060 \\
\hline \multirow{2}{*}{ Pair 2 } & CAL 1 & .623 & 13 & .7748 & .2149 \\
& CAL 2 & .523 & 13 & .4604 & .1277 \\
\hline \multirow{2}{*}{ Pair 3 } & RBL 1 & $1.508^{\mathrm{a}}$ & 13 & .4856 & .1347 \\
& RBL 2 & $1.508^{\mathrm{a}}$ & 13 & .4856 & .1347 \\
\hline
\end{tabular}

a. The correlation and $t$ cannot be computed because the standard error of the difference is 0 .

Table 1 (a). The mean \& SD of the various periodontal parameters using IPS Impress material

\begin{tabular}{|l|l|l|l|l|l|l|}
\hline & Mean & $\begin{array}{c}\text { Std. } \\
\text { Deviation }\end{array}$ & $\mathrm{t}$ & $\mathrm{df}$ & $\begin{array}{c}\text { Sig. (2- } \\
\text { tailed) }\end{array}$ \\
\hline Pair 1 & PD 1 & .3308 & .3276 & 3.641 & 12 & $.003^{*}$ \\
\hline PD 2 & & & & & \\
\hline
\end{tabular}

Table 1 (b). Comparison of change in periodontal parameters with IPS Impress material

\begin{tabular}{|c|c|c|c|c|c|}
\hline \multicolumn{2}{|c|}{} & \multicolumn{5}{|c|}{ Paired Samples Statistics } \\
\hline \multirow{2}{*}{ Pair 1 } & Mean & $\mathrm{N}$ & Std. Deviation & Std. Error Mean \\
& PD 1 & 1.9500 & 60 & .61658 & .07960 \\
\hline \multirow{2}{*}{ Pair 2 } & PD 2 & 1.9817 & 60 & .74162 & .09574 \\
\hline & CAL 1 & 1.8117 & 60 & 1.41566 & .18276 \\
\hline \multirow{2}{*}{ Pair 3 } & CAL 2 & 1.8050 & 60 & 1.21842 & .15730 \\
& RBL 1 & 1.9983 & 60 & .82595 & .10663 \\
\hline
\end{tabular}

Table 2 (a). The mean \& SD of the various periodontal parameters using PFM material

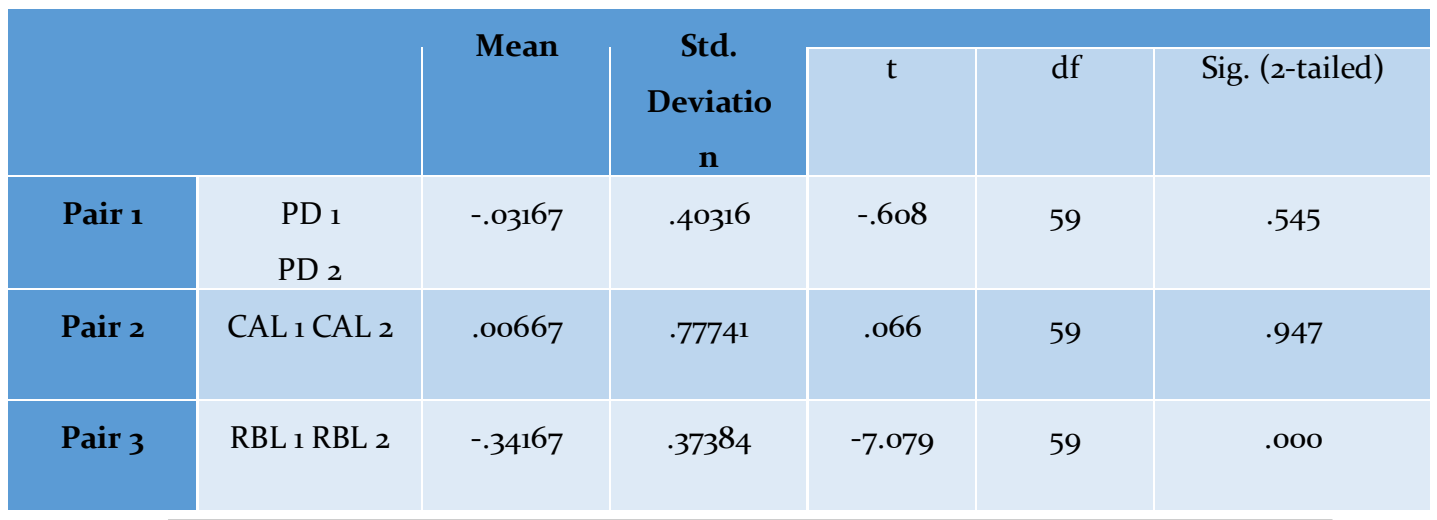

Table 2 (b). Comparison of change in periodontal parameters with PFM material 


\begin{tabular}{|c|c|c|c|c|c|}
\hline \multicolumn{7}{|c|}{} & \multicolumn{7}{c|}{ Paired Samples Statistics } \\
\hline \multirow{2}{*}{ Pair 1 } & & Mean & $\mathrm{N}$ & Std. Deviation & Std. Error Mean \\
& PD 1 & 1.4786 & 14 & .48386 & .12932 \\
\hline \multirow{2}{*}{ Pair 2 } & PD 2 & 1.3500 & 14 & .35464 & .09478 \\
& CAL 1 & .8571 & 14 & .38772 & .10362 \\
\hline \multirow{2}{*}{ Pair 3 } & CAL 2 & .6929 & 14 & .64625 & .17272 \\
\hline & RBL 1 & 1.5214 & 14 & .64829 & .17326 \\
\hline & RBL 2 & 1.7000 & 14 & .56569 & .15119 \\
\hline
\end{tabular}

Table 3 (a). The mean \& SD of the various periodontal parameters using Zirconia material

\begin{tabular}{|c|c|c|c|c|c|c|}
\hline & & Mean & & & & \\
\hline & & & Deviation & $\mathrm{t}$ & $\mathrm{df}$ & Sig. (2-tailed) \\
\hline Pair 1 & $\begin{array}{l}\mathrm{PD}_{1} \\
\mathrm{PD}_{2}\end{array}$ & .12857 & .40274 & 1.194 & 13 & .25 \\
\hline Pair 2 & $\mathrm{CAL}_{1} \mathrm{CAL}_{2}$ & .16429 & .49708 & 1.237 & 13 & .24 \\
\hline Pair 3 & $\mathrm{RBL}_{1} \mathrm{RBL}_{2}$ & -.17857 & .31666 & -2.110 & 13 & .05 \\
\hline
\end{tabular}

Table $_{3}$ (b). Comparison of change in periodontal parameters with Zirconia material

such as IPS empress (E-max) and zirconia are gradually replacing it.

This study was designed to assess the periodontal status of a group of Saudi adult patients following the insertion of FPDs placed on vital abutments. Such an assessment is considered valuable since the FPD is still a very common and economic replacement option for missing teeth especially when implants are contraindicated. Therefore thorough evaluation of the oral health status of such patients is essential to establish effective preventive programs. A preliminary leg of this study was already conducted with endodontically treated abutment teeth using the same materials. ${ }^{12}$

In this leg of the study, it was decided to include only bridges in which the abutment teeth were vital and the crown margins were equigingival. Only 3 unit bridges were included in order to standardize the occlusal load on the abutments and keep it uniform. Bridges with multiple units would have further led to variations in clinical and radiographic parameters owing to variations in the load bearing capacity of the abutments. This made it easier to standardize the study population and perform appropriate measurements both clinically and radiographically as the landmarks could be easily determined for linear measurements.

Vital teeth as abutments pose a few disadvantages like development of periapical pathology. ${ }^{13}$ In addition, sensitivity to hot or cold stimulation may be an occasional, but unwanted consequence of a newly cemented crown or fixed partial denture. Because of sectioning of dentinal tubules, a certain degree of pulpal trauma is inevitable during tooth preparation. Completely avoiding sensitivity is impossible. ${ }^{2}$

Biocompatibility and chemical durability are highly important properties in dental materials. Zirconia ceramics have been reported not to have potential toxic or genotoxic effects ${ }^{14-16}$ and to present satisfactory soft tissue responses. De Baker ${ }^{5}$ reported that it is the baseline periodontal health that determines the long term periodontal success of a fixed restoration irrespective of margin configuration. Van Brakel $\mathrm{R}^{17}$ and Weishaupt et al. ${ }^{18}$ reported that a particular type of alloy may have a stabilizing effect on gingival health irrespective of level of margin placement. Contrary to the 
claim made by Weishaupt, Reitemeier et al. ${ }^{19}$ did not find any effect of the type of alloy on gingival health and reported that type of alloy did not affect the level of plaque accumulation and gingival health was similar around any alloy. Christensen ${ }^{20}$ Kancyper $^{21}$ and Abidi et al. ${ }^{10}$ also concluded that the type of restorative material had no effect on the health of periodontal tissues.

On the basis of such varying evidences, it was decided to assess the effects of recent materials used in fixed prosthesis today on the periodontal status by evaluating the clinical and radiographic status.

Our results revealed that clinically, IPS empress crowns on vital abutment teeth showed better improvement with little or no change in radiologic parameters. On the contrary, PFM and zirconia crowns showed improvement in radiographic bone levels with no significant changes in clinical parameters of attachment level and probing depths. PFM crowns have known to be tissue friendly for many years. However, encouraging results with zirconia crowns strongly suggest that newer materials show definite promise for long term use.

Although a vital pulp and optimal periodontal health ensures the health of the peri radicular areas, not much evidence is available with regard to the long term survival of a vital abutment serving an FPD. Many researchers have suggested that the long-term prognosis of such abutment teeth may be guarded, yet, these teeth serve well if the health of the periodontium is maintained. However, the risk of root caries, post cementation sensitivity and pulpal necrosis still remains with the use of these teeth as abutments. Nevertheless, the type of material used for FPD seemed to have no effect on the periodontal health or the vitality of the abutment teeth.

Limitations: A larger sample size on a larger cross section of the population including both vital and non vital abutments for each material type is recommended for more authenticity in results.

\section{CONCLUSION}

Within the limitations of the study, overall, the type of material used in FDP may not influence the long term periodontal status of vital abutments. PFM and Zirconia materials showed improvement in bone levels of vital abutments whereas abutments with IPS empress showed improvement clinically.

\section{REFERENCES}

1. Aljoharah Al-Sinaidi, Reghunathan S. Preethanath.The effect of fixed partial dentures on periodontal status of abutment teeth. The Saudi Journal for Dental Research 2014;5:104-8.

2. Shenoy KK, Anas B. Post-Cementation Sensitivity in Vital Abutments of Fixed Partial Denture: A Review. Sch J App Med Sci. 2017;5(3D):1009-13.

3. Goga R, Purton DG.The use of endodontically treated teeth as abutments for crowns, fixed partial dentures, or removable partial dentures: a literature review. Quintessence Int. 2007;38(2):e106-11.

4. Cheung GSP, Lai SCN, Ng RPY. Fate of vital pulps beneath a metal-ceramic crown or a bridge retainer. International Endodontic Journal 2005;38:521-30. 10.1111/j.1365-2591.2005.00982.x.

5. De Backer H, Van Maele G, De Moor N, Van den Berghe L. Survival of complete crowns and periodontal health: 18-year retrospective study. Int J Prosthodont. 2007;20:151-8.

6. Chansoria S, Chansoria H. Abutment Selection In Fixed Partial Denture. IOSR Journal of Dental and Medical Sciences (IOSR-JDMS) 2018: 17( 3):4-12.

7. Almotairy M, Almaghrabi F, Alharthy A, Alrashaid H, Diab H, Shibatalhamad Y. Effect of Full Ceramic Crown Versus Ceramic Fused to Metal Crown on Periodontal Tissues Health. EC Dental Science 2018;17(7):1041-6.

8. Pezron I, Kugel G, Laurent-Maquin D, Gangloff S, Egles C. Biocompatibility study of lithium disilicate and zirconium oxide ceramics for esthetic dental abutments. J Periodontal Implant Sci. 2016;46(6):362-1. https://doi.org/10.5051/jpis.2016.46.6.362

9. Valenti M, Valenti A. Retrospective survival analysis of 261 lithium disilicate crowns in a private general practice. Quintessence Int 2009;40:573-9.

10. Abidi Y A, Jameel A, Hasan A , Rashid S. An Evaluation of Association between Crown Margins \& Materials with the Periodontal Health. JPDA 2011; 20:148153.

11. Al-Wahadni AM, Mansour Y, Khader Y.Periodontal response to all-ceramic crowns (IPS Empress) in general practice. Int J Dent Hyg. 2006;4(1):41-6.

12. Shetty S, Shetty K, Wali O, Almarshoud L et al. Comparative Evaluation of Esthetic Materials Used For

Fixed Partial Prosthesis on the Periodontal Status - A One Year Retrospective Follow-UP. International Journal of Medical Science and Advanced Clinical Research (IJMACR) 2019;2(2):84-92.

13. Shankar YR, Srinivas K, Surapaneni HC, Reddy HVS. Prosthodontic Treatment Using Vital and Non-Vital 
Submerged Teeth: Two Case Reports. Journal of Clinical and Diagnostic Research. 2013;7(10): 2396-9.

14. Josset Y, Oum'Hamed Z, Zarrinpour A, Lorenzato M, Adnet JJ, Laurent-Maquin D. In vitro reactions of human osteoblasts in culture with zirconia and alumina ceramics. J Biomed Mater Res 1999;47:481-93.

15. Covacci V, Bruzzese N, Maccauro G, Andreassi C, Ricci GA, Piconi $C$, et al. In vitro evaluation of the mutagenic and carcinogenic power of high purity zirconia ceramic. Biomaterials 1999;20:371-6.

16. Warashina H, Sakano S, Kitamura S, Yamauchi KI, Yamaguchi J, Ishiguro N, et al. Biological reaction to alumina, zirconia, titanium and polyethylene particles implanted onto murine calvaria. Biomaterials 2003;24:3655-61.

17. Van Brakel R, Meijer GJ, Verhoeven JW, Jansen J, de Putter C, Cune MS. Soft tissue response to zirconia and titanium implant abutments: an in vivo within-subject comparison. J Clin Periodontol 2012;39:995-1001.

18. Weishaupt P, Bernimoulin JP, Lange KP, Rothe S, Na umann M, Hagewald S. Cli nica 1 and inflammatory effects of galvano-ceramic and me t a l - ceramic crowns on periodontal tissues. J Oral Rehabil.2007;34:941-7.

19. Reitemeier B, Hansel K, Walter MH, Kastner C, Toutenburg $H$. Effect of posterior crown margin placement on gingival health. J Prosthet Dent. $2002 ; 87: 167-72$.

20. Christensen GJ. Porcelain-fused-to-metal versus zirconia-based ceramic restorations, 2009. J Am Dent Assoc. 2009;140:1036-9.

21. Kancyper SG, Koka S. The influence of intracrevicular crown margins on gingival health: preliminary findings.

J Prosthet Dent 2001;85:461-5.
Source of support: Nil, Conflict of interest: None declared
Cite this article as:

Shetty S, Shetty K, Tayeb R, Abdou J, Fetaihi B, Sheikh KH. Comparative Evaluation of Esthetic Materials Used for Fixed Partial Prosthesis Placed On Vital Abutments On The Periodontal Status: A One Year Retrospective Follow-Up. Int Healthc Res J. 2019;3(5):179-184 https://doi.org/10.26440/IHRJ/0305.08271

\section{AUTHOR AFFILIATIONS:}

BDS, MDS(Periodontics), FICOI, Associate Professor, Dentistry Program, Ibn Sina National College of Medical Sciences, Jeddah, Saudi Arabia BDS, MDS(Prosthodontics), FICOI, Associate Professor, Dentistry Program, Ibn Sina National College of Medical Sciences, Jeddah, Saudi Arabia BDS Student, Dentistry Program, Ibn Sina National College of Medical Sciences, Jeddah, Saudi Arabia

4. B.Sc, M.Sc (Statistics), Quality Assurance Center, Ibn Sina National College of Medical Sciences, Jeddah, Saudi Arabia

\section{*Address of Corresponding Author:}

\section{Dr Shreya Shetty}

Associate Professor

Dentistry Program

Ibn Sina National College of Medical

Sciences

Jeddah, Saudi Arabia

drshreya[at]gmail[dot]com 